\title{
Human placental amino acid transporter genes: expression and function
}

\author{
Yoshiki Kudo and C. A. R. Boyd \\ Department of Human Anatomy and Genetics, University of Oxford, \\ South Parks Road, Oxford OX1 3QX, UK
}

\begin{abstract}
Recent findings on amino acid transporter genes are reviewed with particular focus on matching previously described transport systems to individual genes. Functional studies using cloned and expressed transporters are considered as the critical tool allowing identification of the functional properties of individual genes. Specifically, these experiments allow identification of the transported substrate amino acids and of the transport mechanism. We focus on the very recent discovery and properties of the heterodimeric family of amino acid transport proteins where two subunits encoded in different genes are required. For these transporters, co-expression of both subunits is mandatory for functional studies. The field of placental amino acid transport is further complicated by complexities arising from both gestational age-specific and species-specific gene expression. The function of the transporter also depends on its cellular localization in the trophoblast. In addition, for transporters that are coupled to ion gradients, both membrane potential and ion pumping will contribute to the rate of amino acid delivery to the fetus. Regulation of function is important not only for fetal nutrition but also for specific additional aspects of placental biology.
\end{abstract}

This short review attempts to place in context recent experimental work on amino acid transporters in human placenta. These transporters are of interest to reproductive biologists as through their integrated function they provide the fetus with the unique group of nutrients (amino acids) required for protein synthesis. Of the 20 amino acids that can charge specific tRNAs (and are thus necessary and sufficient for protein synthesis), some can be produced from precursors at rates sufficient to match their individual rate of utilization during synthesis of new protein. This is not true for the 'essential' amino acids, which must therefore be delivered to growing tissues if they are not to limit the rate of cellular protein synthesis. For normal growth in childhood, the group of such nutritionally essential amino acids is Arg, Val, His, Ile, Leu, Lys, Met, Phe, Trp and Thr. However, the high rates of protein synthesis that occur in the fetus in utero mean that the group of amino acids that must be delivered across the placenta will include others that may be nonessential in adult life. Thus, net transplacental delivery of this substantial group of amino acids to the growing tissues of the conceptus is essential for normal fetal growth and requires transporter gene expression, with appropriate synthesis and membrane insertion of these transporter (carrier) molecules. These amino acid transporters are not specific for one individual amino acid but instead recognize 'groups' of cognate amino acids (defined by the 'substrate specificity' of the individual transporter). Thus, transporters

Email: yoshiki.kudo@human-anatomy.oxford.ac.uk may have overlapping specificities and an individual amino acid may be a substrate for several 'transport systems' (the phenotypic characterization of an individual transporter). Transport systems are characterized into those that are coupled to the electrochemical gradient of sodium ions through co-transport with $\mathrm{Na}^{+}$('sodium-coupled transporters') and those that are not ('sodium-independent transporters').

For cellular protein synthesis to proceed, all 20 tRNAs need to be charged simultaneously. Therefore, there must be homeostasis of the plasma concentrations of all 20 amino acids, and it is not surprising that a number of placental amino acid transporters function as 'exchangers' allowing movement across the plasma membrane of one amino acid in exchange for another. There is dispute about whether members of this group of transporters act solely as exchangers (that is, function as 'obligatory exchangers') or whether they can also produce the net transport of amino nitrogen required for fetal growth.

In humans, the placental barrier between maternal and fetal circulations is made by the trophoblast, which acts as an unusual epithelium separating the maternal circulation from the fetal circulation. The apical (brush border) membrane of the syncytiotrophoblast lies in direct contact with maternal blood, whereas the basal membrane of the trophoblast faces the fetal circulation flowing through the umbilical circulation in the placental chorionic villi. Co-ordinated activity of amino acid transporters in both of these membranes is required for net transport of amino acid across this epithelium. 


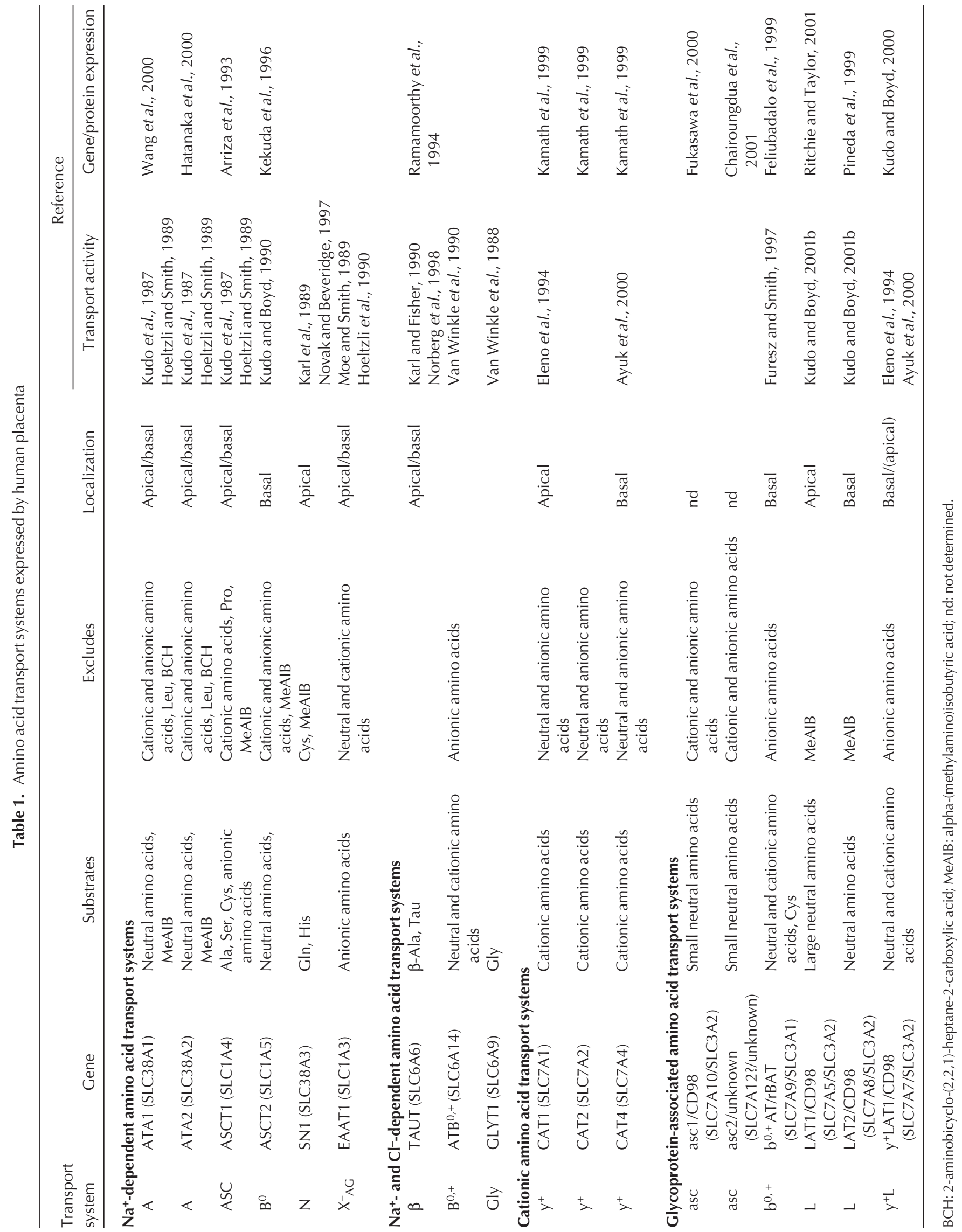


The topic of placental amino acid transporters has become of considerable recent interest in biomedical research because of the discovery of the effects of intrauterine growth on postnatal development and associated patterns of adult morbidity and mortality (Godfrey and Barker, 2000; Barker, 2001). Moreover, placental amino acid transport is also implicated in aspects of development unrelated to fetal nutrition, for example, in trophoblast differentiation (Lavillette et al., 2002) and in intra-uterine immunology (Kudo and Boyd, 2001a).

In this review, particular focus will be placed on studies in this area of research performed since the paper of Jansson (2001). There have been excellent general reviews on placental transporters, for example on transporters involved in transplacental drug delivery (Ganapathy et al., 2000) and placental glucose transporters (IIlsley, 2000), which are also relevant to the topic considered here.

\section{Heterodimeric transporters}

One of the particularly interesting developments in the area of amino acid transport has been the discovery of a family of dimeric proteins that catalyse, through their specific light chains, a wide spectrum of amino acid transport across the cell membrane of a wide variety of tissues including the human placental trophoblast. This family of molecules has been the subject of intense experimental work during the last 3 years following the pioneering description by Mastroberardino et al. (1998). This work has led to a flurry of reviews including those of Verrey et al. (2000), Devés and Boyd (2000), Kanai and Endou (2001), Chillaron et al. (2001), Wagner et al. (2001) and Meier et al. (2002). The known amino acid transporters in human trophoblast are shown (Table 1) and the properties of these transport systems are indicated with respect to substrate specificity and sodium dependence. The transport systems that are heterodimeric are also shown (Tables 1 and 2). Two heavy chains (either rBAT or CD98, known also as 4F2hc) form heterodimers with the family of light chains. The light chains specify the function of the transport complex, whereas the heavy chain appears to specify the apical or basal location of the transport system. In all epithelia studied to date the transporter complexes comprising rBAT as the heavy chain are localized to the apical membrane, whereas those in which CD98 (4F2) is the heavy chain are located basally.

In trophoblast, Ayuk et al. (2000) (see also Ayuk et al., 2002) showed how different transporters contribute to transplacental cationic amino acid delivery. In the apical membrane transport system, $\mathrm{y}^{+}$(encoded in genes of the CAT family) is the dominant pathway. This is a sodium-independent system that is electrogenic so that the membrane potential (inside negative) contributes to the uptake of this positively charged group of amino acids (lysine and arginine). In the basal membrane, the heterodimeric transporter encoding system $\mathrm{y}^{+} \mathrm{L}$ is predominant. (As this system has the unusual property of accepting charged amino acids in the absence of sodium while also translocating neutral amino acids only when sodium is present, system $y^{+} L$ provides an effective electroneutral exit pathway for lysine and arginine.) However, in other epithelia in which system $\mathrm{y}^{+} \mathrm{L}$ also predominates in the basal plasma membrane, it is clear that the associated heavy chain is CD98. Thus, the immunocytochemical localization of CD98 in trophoblast is unexpected. Ayuk et al. (2000) showed by western blot analysis that this heavy chain, known to be required for $y^{+}$LAT1 trafficking to the basal membrane in all other epithelia, was not detectable as antigen-displaceable immunoreactivity in basal plasma membrane preparations, but was detectable in the apical membrane vesicles. Okamoto et al. (2002) used immunohistochemistry and also found staining for this heavy chain at the apical surface. In contrast, using a different antibody (see Fig. 1) J. L. Millo and C. A. R. Boyd (unpublished) found strong basal staining for this heavy chain in term human placental villi. As Kudo and Boyd (2001b) showed that the amino acid transport system $L$ was functionally detected in both isolated membrane vesicles prepared from the brush border and from basal surfaces, it appears that there is an important issue that remains to be resolved: that functional studies showed that the isoforms of system $\mathrm{L}$ in the brush border are distinct from those found in the basal membrane. Thus, system $L$ in the brush border membrane behaved with the properties expected of the expressed amino acid transport system encoded by the LAT-1 light chain, whereas the basal surface behaved with the properties expected of the LAT-2 light chain. Specifically, small neutral amino acids such as alanine were inhibitors of basal transport only (see Fig. 2). Such findings raise a question: how can a single heavy chain (CD98) transport different light chains to different membranes? As both LAT1 and LAT2 transport only with CD98, it follows that something is lacking in our understanding of the process of system $\mathrm{L}$ isoform distribution in the human trophoblast. Is it possible that CD98 heavy chain is not the only heavy chain expressed in the trophoblast? This proposal is not implausible given the intriguing recent finding that three novel light chains, asc2 (Chairoungdua et al., 2001), AGT1 (Matsuo et al., 2002) and XAT (Blondeau, 2002), are expressed in mouse kidney transport with a novel, as yet unknown, heavy chain that is neither CD98 nor rBAT. The conflicting reports concerning the immunolocalization of CD98hc might have a ready resolution if the antibodies used in the studies of J. L. Millo and C. A. R. Boyd (unpublished) and Okamoto et al. (2002) do not or do crossreact, respectively, with the proposed missing heavy chain. It is interesting that a similar discrepancy in the literature concerning localization of the $\mathrm{Na}^{+}-\mathrm{K}^{+}$-ATPase in trophoblast appears to have been resolved in recent careful studies showing isoform localization to both membranes (Persson et al., 2002).

What might be the function of heterodimeric amino acid transporters in placenta? Meier et al. (2002) have shown that system L (both isoforms) appears to perform only coupled transport in an oocyte expression system. Although 



Fig. 1. Immunohistochemistry of CD98 in chorionic villi of human term placenta. (a) Trophoblast shows prominent immunoreactivity at the basal surface of the syncytium as well as less prominent staining of the apical surface (J. L. Millo and C. A. R. Boyd, unpublished). (b) Trophoblast shows immunoreactivity at the apical surface of the syncytium as well as less prominent staining of the basal surface. (Reproduced with permission from Okamoto et al., 2002.) Scale bar represents $20 \mu \mathrm{m}$.

Table 2. Light chains for the heterodimeric amino acid transport systems expressed by human placenta

\begin{tabular}{|c|c|c|c|c|c|}
\hline \multirow[b]{2}{*}{ Light chain } & \multirow{2}{*}{$\begin{array}{l}\text { Transport } \\
\text { system }\end{array}$} & \multirow[b]{2}{*}{ Localization } & \multirow[b]{2}{*}{ Transport function } & \multicolumn{2}{|c|}{ Reference } \\
\hline & & & & Transport activity & Gene/protein expression \\
\hline \multicolumn{6}{|c|}{ Light chain associated with CD98 } \\
\hline LAT1 & $\mathrm{L}$ & Apical & $\mathrm{Na}^{+}$-independent: large neutral amino acids & Kudo and Boyd, 2001b & $\begin{array}{l}\text { Mastroberardino et al., } 1998 \\
\text { Richie and Taylor, } 2001\end{array}$ \\
\hline LAT2 & $\mathrm{L}$ & Basal & $\begin{array}{l}\mathrm{Na}^{+} \text {-independent: large and small neutral } \\
\text { amino acids }\end{array}$ & Kudo and Boyd, 2001b & Pineda et al., 1999 \\
\hline $\mathrm{y}^{+}$LAT1 & $y^{+} L$ & Basal/(apical) & $\begin{array}{l}\mathrm{Na}^{+} \text {-independent: cationic amino acids } \\
\mathrm{Na}^{+} \text {-dependent: large neutral amino acids }\end{array}$ & Ayuk et al., 2000 & Torrents et al., 1998 \\
\hline asc1 & asc & nd & $\begin{array}{l}\mathrm{Na}^{+} \text {-independent: small neutral amino acids } \\
\mathrm{D} \text {-isomers of small neutral amino acids }\end{array}$ & & Fukasawa et al., 2000 \\
\hline \multicolumn{6}{|c|}{ Light chain associated with rBAT } \\
\hline $\mathrm{b}^{0,+} \mathrm{AT}$ & $b^{0,+}$ & Basal & $\begin{array}{l}\mathrm{Na}^{+} \text {-independent: neutral and cationic amino } \\
\text { acids, cysteine }\end{array}$ & Furesz and Smith, 1997 & Feliubadalo et al., 1999 \\
\hline \multicolumn{6}{|c|}{$\begin{array}{l}\text { Light chain associated with } \\
\text { unknown heavy chain }\end{array}$} \\
\hline asc2 & asc & nd & $\mathrm{Na}^{+}$-independent: small neutral amino acids & & Chairoungdua et al., 2001 \\
\hline
\end{tabular}

nd: not determined.

their striking results fit with the known strong exchange properties characteristic of 'native' system $\mathrm{L}$ as established in many functional studies during the last 20 years (for an example, see Shotwell et al., 1983), their findings indicate that system $L$ cannot generate net transport of amino acids across the placenta. However, because oocyte studies must necessarily be performed at a temperature lower than that in mammalian tissue in vivo, it is still appropriate to be somewhat guarded in excluding the possible role of heterodimeric transporters in achieving net rather than exchange transport. Thus, early work on leucine transport in red blood cells (Hoare, 1972) showed that temperature was a major factor influencing exchange versus net capability. Moreover, the experiments of Segawa et al. (1999), who found net amino acid efflux through LAT-2 co-expressed (in oocytes) with CD98, are in contrast to the findings of Pineda et al. (1999) and Meier et al. (2002). This discrepancy indicates that it will be important not to overlook the possibility that additional factors (for example, regulatory proteins) might be required for net transport through system $L$ in placenta as in other epithelia.

System L (for a review, see Wagner et al., 2001) has a possible additional role in placental biology. System L amino acid transporters may couple changes in extracellular tryp- 


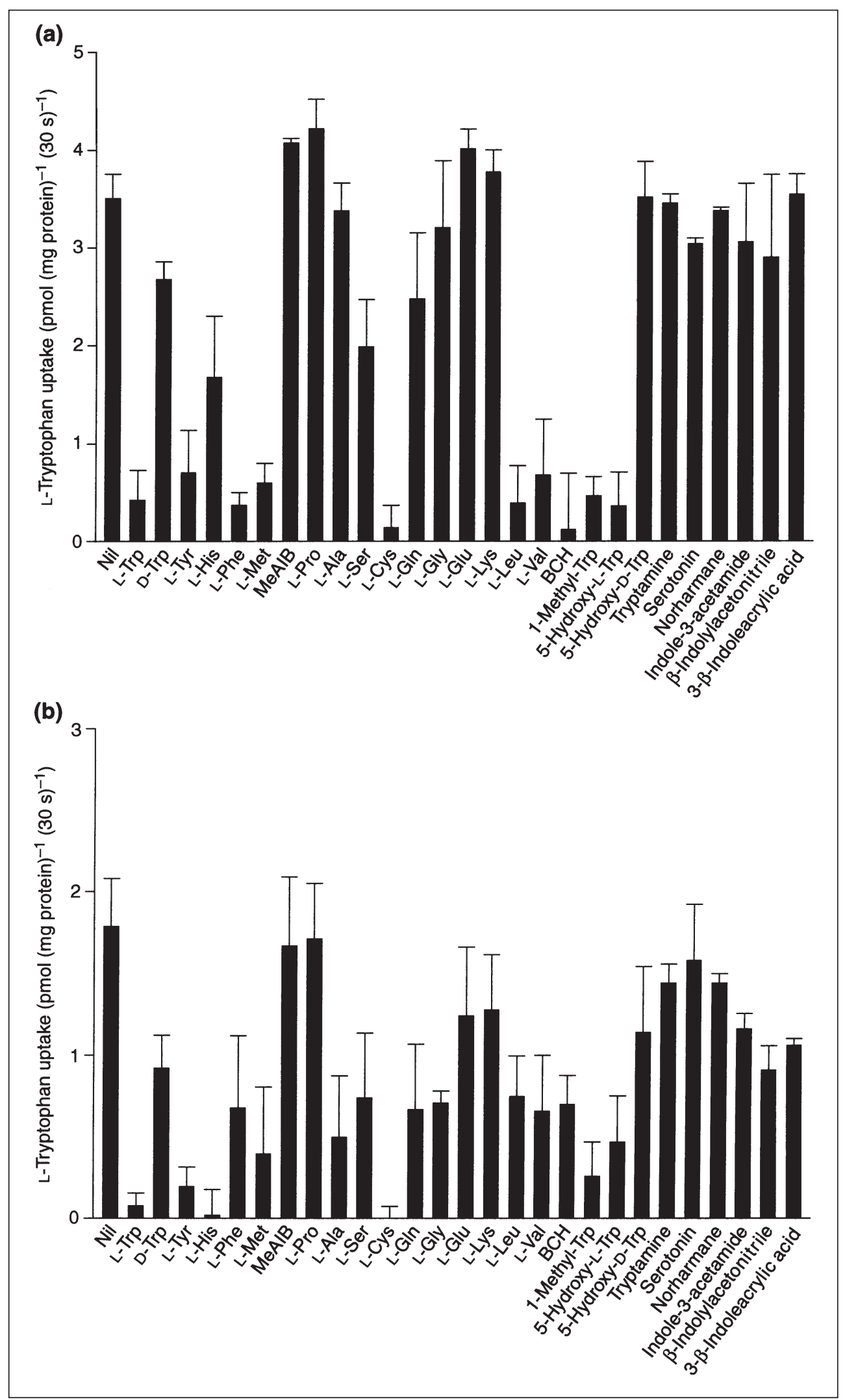

Fig. 2. Functional analysis of tryptophan influx through system $L$ into isolated (a) apical or (b) basal membrane vesicles. Note the inhibition by small neutral amino acids, such as alanine and serine, in basal but not in apical membranes, showing the functional fingerprint of the light chain LAT2 in basal and LAT1 in apical membranes (Redrawn from Kudo and Boyd, 2001b). 
tophan (outside the trophoblast in the maternal intervillous space) to indoleamine 2,3-dioxygenase (IDO)-mediated tryptophan degradation within the trophoblast. The seminal study of Munn et al. (1998) established (in mouse) the importance to reproductive immunology of IDO-mediated specific depletion of this particular amino acid. These authors showed that when this catabolic pathway was disrupted pharmacologically (with 1-methyl-tryptophan, a specific inhibitor of IDO), normal implantation and subsequent successful pregnancy did not occur. However, this effect was confined to allogeneic matings producing conceptuses able to express distinct paternally inherited alleles. In syngeneic matings, 1-methyl-tryptophan was without effect, but when such syngeneic conceptuses were transgenically manipulated to express immunologically distinct surface antigens, the IDO inhibitor was able to abrogate successful implantation.

Subsequent work by Kudo and colleagues (for a review, see Kudo and Boyd, 2001a) indicated that a similar mechanism might occur in established human pregnancy, as all the component mechanisms established for IDO-mediated immunosuppression of the maternal immune response against the fetus in mice are also found in human placenta. This finding indicates that inhibitors of system $L$ amino acid transport in human placenta (for example, by 2-aminobicyclo-(2,2,1)-heptane-2-carboxylic acid (BCH)) might, like 1-methyl-tryptophan (by inhibiting the normal maternal immune response), be effective abortificients. At the earliest stages of implantation, van Winkle (2001) has suggested that systems $\mathrm{B}^{0,+}$ and $\mathrm{b}^{0,+}$ might be important for tryptophan transport and for access of 1-methyl-tryptophan to IDO.

\section{Sodium-coupled transporters}

There has been important recent work on amino acid transporters other than those that are heterodimeric. Cramer et al. (2002) have shown that system A is important for fetal growth in rats, as when it was inhibited by a competitive non-metabolized substrate infused into the mother during days 7-20 of gestation, fetal growth was significantly decreased. System A has been cloned from the placenta (Wang et al., 2000) and the importance of this transporter to mammalian pregnancy supports earlier work showing that the rate of system A-mediated amino acid transport in the placenta of babies with intra-uterine growth retardation is significantly reduced. Thus, uptake of non-metabolized amino acid (aminoisobutyric acid AIB or methyl-AIB) into brush membrane vesicles of placentae from such pregnancies was significantly reduced compared with controls (Dicke and Henderson, 1988; Mahendran et al., 1993). In the work of Mahendran et al. (1993), the effect on system A amino acid transport was apparently specific, as other systems studied did not show this effect. Since these papers were published, further studies have demonstrated altered amino acid transport in placentae associated with growth-restricted babies (Glazier et al., 1997; Godfrey et al., 1998; Jansson et al., 1998; Norberg et al., 1998).
Glutamate transport has also been studied in rodent models and rat placental transport of this amino acid appears to be predominately through system $\mathrm{X}^{-}{ }_{\mathrm{AG}}$ (Matthews et al., 1998, 1999), the role of which in placenta has up until now been studied little. It will be interesting to determine whether regulation of system $\mathrm{X}^{-}{ }_{\mathrm{AG}}$ in placenta involves amino acid response elements linked to amino acid deprivation, as described by Franchi-Gazzola et al. (1996).

\section{Sodium-independent transporters}

System $\mathrm{y}^{+}$has been studied in placenta by Ayuk et al. (2000) and the underlying molecular processes are reviewed by Closs (2002). There are various isoforms of system $y^{+}$, specifically CAT-1, CAT-2 and CAT-4, and all three of these genes are expressed at the mRNA level in human placenta (Kamath et al., 1999). It is interesting that this system, which catalyses the uptake of the essential cationic acids (lysine, arginine and histidine) is sodium-independent yet electrogenic. The straightforward explanation for this (see Devés and Boyd, 1998) is that translocation of the substrate itself generates current flow; hence, the membrane potential (trophoblast inside negative, see Birdsey et al., 1999) provides the driving force for accumulation of such amino acids. The mechanism by which these cationic amino acids leave across the trophoblast basal membrane requires a different system, as here the trophoblast potential will oppose rather than aid movement of such cations across the cell membrane. That this is the site of functional expression of the amino acid transporter system $y^{+} L$ (originally described in red blood cells (Déves et al., 1992) and more recently in human placenta (Eleno et al., 1994; Ayuk et al., 2000)) and that this transport system is electroneutral provides a ready solution to this conundrum. In fact, system $\mathrm{y}^{+} \mathrm{L}$ is a transporter for cationic amino acids that is able to exchange these cationic amino acids against sodiumcoupled neutral amino acid flux (for example, glutamine, leucine), providing a natural route for efflux across epithelial cell membranes, as originally proposed by Boyd (1992) and subsequently confirmed by Pineda et al. (1999) and Kanai et al. (2000). System $y^{+} L$ is a member of the CD98 heterodimeric transporter family (Table 2 ) and these findings support further investigation into the nature and distribution of the heavy chain family in placenta.

\section{Conclusion}

Constancia et al. (2002) have shown that delivery of alpha(methylamino)isobutyric acid (alpha-methyl-AIB) through system $A$ to the fetus is reduced when the paternally expressed insulin-like growth factor II gene is deleted. This finding indicates that this imprinted gene controls the placental supply of maternal nutrients to the mammalian fetus. Therefore, it will be important to investigate the molecular mechanisms altering system A transporter activity, as these must be involved in the processes by 
which maternal-paternal genetic conflict is both generated and regulated. It will also be interesting to determine whether other placental transporters, including those reviewed here, are similarly regulated through this or other paternally imprinted genes. Other areas that need further work include changes in amino acid transport during development, particularly in the early stages of implantation. Study of how the expression of different transporter genes is coordinated is also lacking. It is striking that at the present no abnormal phenotype is related to abnormalities of amino acid transporter genes, emphasizing the importance of future studies that bring together cell biologists and clinical obstetricians.

\section{References}

Key references are indicated by asterisks.

Arriza JL, Kavanaugh MP, Fairman WA, Wu YN, Murdoch GH, North RA and Amara SG (1993) Cloning and expression of a human neutral amino acid transporter with structural similarity to the glutamate transporter gene family Journal of Biological Chemistry 26815 329-15 332

Ayuk PT, Sibley CP, Donnai P, D'Souza S and Glazier JD (2000) Development and polarization of cationic amino acid transporters and regulators in the human placenta American Journal of Physiology and Cell Physiology 278 C1162-C1171

Ayuk PTY, Theophanous D, D'Souza SW, Sibley CP and Glazier JD (2002) L-arginine transport by the microvillous plasma membrane of the syncytiotrophoblast from human placenta in relation to nitric oxide production: effects of gestation, pre-eclampsia, and intrauterine growth restriction Journal of Clinical Endocrinology and Metabolism 87 $747-751$

Barker DJ (2001) The malnourished baby and infant British Medical Bulletin 60 69-88

Birdsey TJ, Boyd RD, Sibley CP and Greenwood SL (1999) Effect of hyposmotic challenge on microvillous membrane potential in isolated human placental villi American Journal of Physiology 276 R1479-R1488

Blondeau JP (2002) Homologues of amino acid permeases: cloning and tissue expression of XAT1 and XAT2 Gene 286 241-248

Boyd CAR (1992) Cationic amino acid transport; some recent studies Physiological Society Magazine 7 32-36

Chairoungdua A, Kanai Y, Matsuo H, Inatomi J, Kim DK and Endou H (2001) Identification and characterization of a novel member of the heterodimeric amino acid transporter family presumed to be associated with an unknown heavy chain Journal of Biological Chemistry 276 49 390-49399

Chillaron J, Roca R, Valencia A, Zorzano A and Palacin M (2001) Heteromeric amino acid transporters: biochemistry, genetics, and physiology American Journal of Physiology and Renal Physiology 281 F995-F1018

Closs El (2002) Expression, regulation and function of carrier proteins for cationic amino acids Current Opinion in Nephrology and Hypertension 11 99-107

${ }^{*}$ Constancia M, Hemberger M, Hughes J et al. (2002) Placental-specific IGF-II is a major modulator of placental and fetal growth Nature $\mathbf{4 1 7}$ 945-948

*Cramer S, Beveridge M, Kilberg M and Novak D (2002) Physiological importance of system A-mediated amino acid transport to rat fetal development American Journal of Physiology and Cell Physiology $\mathbf{2 8 2}$ C153-C160

Devés R and Boyd CAR (1998) Transporters for cationic amino acids in animal cells: discovery, structure, and function Physiological Reviews 78 487-545

Devés R and Boyd CAR (2000) Surface antigen CD98(4F2): not a single membrane protein, but a family of proteins with multiple functions Journal of Membrane Biology 173 165-177
Devés R, Chavez P and Boyd CAR (1992) Identification of a new transport system $(y+L)$ in human erythrocytes that recognizes lysine and leucine with high affinity Journal of Physiology 454 491-501

Dicke JM and Henderson GI (1988) Placental amino acid uptake in normal and complicated pregnancies American Journal of Medical Science 295 223-227

Eleno N, Déves R and Boyd CAR (1994) Membrane potential dependence of the kinetics of cationic amino acid transport systems in human placenta Journal of Physiology 479 291-300

Feliubadalo L, Font M, Purroy J et al. (1999) Non-type I cystinuria caused by mutations in SLC7A9, encoding a subunit (bo,+AT) of rBAT. International Cystinuria Consortium Nature Genetics 23 52-57

Franchi Gazzola R, Visigalli R, Bussolati O and Gazzola GC (1996) Involvement of protein kinase Cepsilon in the stimulation of anionic amino acid transport in cultured human fibroblasts Journal of Biological Chemistry 27126 124-26130

Fukasawa Y, Segawa H, Kim JY, Chairoungdua A, Kim DK, Matsuo H, Cha SH, Endou H and Kanai Y (2000) Identification and characterization of a $\mathrm{Na}\left({ }^{+}\right)$-independent neutral amino acid transporter that associates with the 4F2 heavy chain and exhibits substrate selectivity for small neutral Dand L-amino acids Journal of Biological Chemistry 275 9690-9698

Furesz TC and Smith CH (1997) Identification of two leucine-sensitive lysine transport activities in human placental basal membrane Placenta 18 649-655

Ganapathy V, Prasad PD, Ganapathy ME and Leibach FH (2000) Placental transporters relevant to drug distribution across the maternal-fetal interface Journal of Pharmacology and Experimental Therapeutics 294 413-420

Glazier JD, Cetin I, Perugino G, Ronzoni S, Grey AM, Mahendran D, Marconi AM, Pardi G and Sibley CP (1997) Association between the activity of the system $\mathrm{A}$ amino acid transporter in the microvillous plasma membrane of the human placenta and severity of fetal compromise in intrauterine growth restriction Pediatric Research 42 514-519

Godfrey KM and Barker DJ (2000) Fetal nutrition and adult disease American Journal of Clinical Nutrition 71 1344s-1352s

Godfrey KM, Matthews N, Glazier J, Jackson A, Wilman C and Sibley CP (1998) Neutral amino acid uptake by the microvillous plasma membrane of the human placenta is inversely related to fetal size at birth in normal pregnancy Journal of Clinical Endocrinology and Metabolism 83 3320-3326

Hatanaka T, Huang W, Wang H, Sugawara M, Prasad PD, Leibach FH and Ganapathy V (2000) Primary structure, functional characteristics and tissue expression pattern of human ATA2, a subtype of amino acid transport system A Biochimica et Biophysica Acta 1467 1-6

Hoare DG (1972) The temperature dependence of the transport of L-leucine in human erythrocytes Journal of Physiology 221 331-348

Hoeltzli SD and Smith CH (1989) Alanine transport systems in isolated basal plasma membrane of human placenta American Journal of Physiology 256 C630-C637

Hoeltzli SD, Kelley LK, Moe AJ and Smith CH (1990) Anionic amino acid transport systems in isolated basal plasma membrane of human placenta American Journal of Physiology 259 C47-C55

Illsley NP (2000) Glucose transporters in the human placenta Placenta 21 $14-22$

*Jansson T (2001) Amino acid transporters in the human placenta Pediatric Research 49 141-147

Jansson T, Scholtbach V and Powell TL (1998) Placental transport of leucine and lysine is reduced in intrauterine growth restriction Pediatric Research 44 532-537

Kamath SG, Furesz TC, Way BA and Smith CH (1999) Identification of three cationic amino acid transporters in placental trophoblast: cloning, expression, and characterization of hCAT-1 Journal of Membrane Biology 171 55-62

Kanai Y and Endou H (2001) Heterodimeric amino acid transporters: molecular biology and pathological and pharmacological relevance Current Drug Metabolism 2 339-354

Kanai Y, Fukasawa Y, Cha SH et al. (2000) Transport properties of a system $\mathrm{y}+\mathrm{L}$ neutral and basic amino acid transporter. Insights into the mechanisms of substrate recognition Journal of Biological Chemistry 275 $20787-20793$ 
Karl PI and Fisher SE (1990) Taurine transport by microvillous membrane vesicles and the perfused cotyledon of the human placenta American Journal of Physiology $\mathbf{2 5 8}$ C443-C451

Karl PI, Tkaczevski H and Fisher SE (1989) Characteristics of histidine uptake by human placental microvillous membrane vesicles Pediatric Research 25 19-26

Kekuda R, Prasad PD, Fei YJ, Torres Zamorano V, Sinha S, Yang Feng TL, Leibach FH and Ganapathy V (1996) Cloning of the sodium-dependent, broad-scope, neutral amino acid transporter Bo from a human placental choriocarcinoma cell line Journal of Biological Chemistry 27118 657-18661

Kudo Y and Boyd CAR (1990) Characterization of amino acid transport systems in human placental basal membrane vesicles Biochimica et Biophysica Acta 1021 169-174

Kudo Y and Boyd CAR (2000) Heterodimeric amino acid transporters: expression of heavy but not light chains of CD98 correlates with induction of amino acid transport systems in human placental trophoblast Journal of Physiology 523 13-18

Kudo Y and Boyd CAR (2001a) The physiology of immune evasion during pregnancy; the critical role of placental tryptophan metabolism and transport Pflugers Archive-European Journal of Physiology 442 639-641

Kudo Y and Boyd CAR (2001b) Characterisation of L-tryptophan transporters in human placenta: a comparison of brush border and basal membrane vesicles Journal of Physiology 531 405-416

Kudo Y, Yamada K, Fujiwara A and Kawasaki T (1987) Characterization of amino acid transport systems in human placental brush-border membrane vesicles Biochimica et Biophysica Acta 904 309-318

Lavillette D, Marin M, Ruggieri A, Mallet F, Cosset FL and Kabat D (2002) The envelope glycoprotein of human endogenous retrovirus type $\mathrm{W}$ uses a divergent family of amino acid transporters/cell surface receptors Journal of Virology 76 6442-6452

Mahendran D, Donnai P, Glazier JD, D'Souza SW, Boyd RD and Sibley CP (1993) Amino acid (system A) transporter activity in microvillous membrane vesicles from the placentas of appropriate and small for gestational age babies Pediatric Research 34 661-665

Mastroberardino L, Spindler B, Pfeiffer R, Skelly PJ, Loffing J, Shoemaker CB and Verrey F (1998) Amino-acid transport by heterodimers of 4F2hc/CD98 and members of a permease family Nature 395 288-291

Matsuo H, Kanai Y, Kim JY et al. (2002) Identification of a novel $\mathrm{Na}^{+}$independent acidic amino acid transporter with structural similarity to the member of a heterodimeric amino acid transporter family associated with unknown heavy chains Journal of Biological Chemistry 27721 017-21026

Matthews JC, Beveridge MJ, Malandro MS, Rothstein JD, Campbell Thompson M, Verlander JW, Kilberg MS and Novak DA (1998) Activity and protein localization of multiple glutamate transporters in gestation day 14 vs day 20 rat placenta American Journal of Physiology 274 C603-C614

Matthews JC, Beveridge MJ, Dialynas E, Bartke A, Kilberg MS and Novak DA (1999) Placental anionic and cationic amino acid transporter expression in growth hormone overexpressing and null IGF-II or null IGF-I receptor mice Placenta 20 639-650

Meier C, Ristic Z, Klauser S and Verrey F (2002) Activation of system L heterodimeric amino acid exchangers by intracellular substrates $E M B O$ Journal 21 580-589

Moe AJ and Smith CH (1989) Anionic amino acid uptake by microvillous membrane vesicles from human placenta American Journal of Physiology 257 C1005-C1011

*Munn DH, Zhou M, Attwood JT, Bondarev I, Conway SJ, Marshall B,
Brown C and Mellor AL (1998) Prevention of allogeneic fetal rejection by tryptophan catabolism Science 281 1191-1193

Norberg S, Powell TL and Jansson T (1998) Intrauterine growth restriction is associated with a reduced activity of placental taurine transporters Pediatric Research 44 233-238

Novak DA and Beveridge MJ (1997) Glutamine transport in human and rat placenta Placenta 18 379-386

Okamoto Y, Sakata M, Ogura K, Yamamoto T, Yamaguchi M, Tasaka K, Kurachi H, Tsurudome $\mathbf{M}$ and Murata $\mathbf{Y}$ (2002) Expression and regulation of 4F2hc and hLAT1 in human trophoblasts American Journal of Physiology and Cell Physiology 282 C196-C204

Persson A, Johansson M, Jansson T and Powell TL (2002) $\mathrm{Na}(+) / \mathrm{K}(+)$-ATPase activity and expression in syncytiotrophoblast plasma membranes in pregnancies complicated by diabetes Placenta 23 386-391

Pineda M, Fernandez E, Torrents D, Estevez R, Lopez C, Camps M, Lloberas J, Zorzano A and Palacin M (1999) Identification of a membrane protein, LAT-2, that co-expresses with 4F2 heavy chain, an L-type amino acid transport activity with broad specificity for small and large zwitterionic amino acids Journal of Biological Chemistry 27419 738-19 744

Ramamoorthy S, Leibach FH, Mahesh VB, Han H, Yang Feng T, Blakely RD and Ganapathy V (1994) Functional characterization and chromosomal localization of a cloned taurine transporter from human placenta Biochemical Journal 300 893-900

Ritchie JW and Taylor PM (2001) Role of the System L permease LAT1 in amino acid and iodothyronine transport in placenta Biochemical Journal $356719-725$

Segawa H, Fukasawa Y, Miyamoto K, Takeda E, Endou H and Kanai $\mathrm{Y}$ (1999) Identification and functional characterization of a $\mathrm{Na}^{+}$ independent neutral amino acid transporter with broad substrate selectivity Journal of Biological Chemistry 27419 745-19 751

Shotwell MA, Kilberg MS and Oxender DL (1983) The regulation of neutral amino acid transport in mammalian cells Biochimica et Biophysica Acta 737 267-284

Torrents D, Estevez R, Pineda M, Fernandez E, Lloberas J, Shi YB, Zorzano A and Palacin $\mathbf{M}$ (1998) Identification and characterization of a membrane protein $(y+L$ amino acid transporter- 1$)$ that associates with $4 \mathrm{~F} 2 \mathrm{hc}$ to encode the amino acid transport activity $\mathrm{y}+\mathrm{L}$. A candidate gene for lysinuric protein intolerance Journal of Biological Chemistry 27332 437-32 445

Van Winkle LJ (2001) Amino acid transport regulation and early embryo development Biology of Reproduction 64 1-12

Van Winkle LJ, Haghighat N, Campione AL and Gorman JM (1988) Glycine transport in mouse eggs and preimplantation conceptuses Biochimica et Biophysica Acta $941241-256$

Van Winkle LJ, Campione AL and Farrington BH (1990) Development of system $\mathrm{BO},+$ and a broad-scope $\mathrm{Na}(+)$-dependent transporter of zwitterionic amino acids in preimplantation mouse conceptuses Biochimica et Biophysica Acta 1025 225-233

Verrey F, Meier C, Rossier G and Kuhn LC (2000) Glycoprotein-associated amino acid exchangers: broadening the range of transport specificity Pflugers Archive - European Journal of Physiology 440 503-512

*Wagner CA, Lang F and Broer S (2001) Function and structure of heterodimeric amino acid transporters American Journal of Physiology and Cell Physiology 281 C1077-C1093

Wang H, Huang W, Sugawara M, Devoe LD, Leibach FH, Prasad PD and Ganapathy V (2000) Cloning and functional expression of ATA1, a subtype of amino acid transporter A, from human placenta Biochemical and Biophysical Research Communications 273 1175-1179 